\title{
Law, Social Justice, and Marriage: An Anti-Essentialist View
}

\author{
Omar Swartz ${ }^{1}$
}

What we today define as "traditional marriage" was essentialist and grounded in a profound sexism that we have since overcome, making marriage and family life much more egalitarian and just in comparison to the past. Reviewing this sexism - as well as the racism we find in the anti-miscegenation laws - and understanding why we no longer practice them officially will help readers to understand the problems with essentialist views of marriage in general, and help us to perceive the wisdom of removing the homophobic elements from the institution of marriage. I offer an alternative lens-nonessentialism-for describing marriage and family, one that frees us from the rigid thinking of the past, which has resulted in so much preventable human suffering by arbitrarily limiting our humanity and our ability to form healthy relationships with one another. [Article copies available for a fee from The Transformative Studies Institute. E-mail address: journal@transformativestudies.org Website: http://www.transformativestudies.org (C2016 by The Transformative Studies Institute. All rights reserved.]

KEYTERMS: American Legal History, Anti-Essentialism, Homophobia, Marriage Equality, Sexism.

At the forefront of the culture wars today in the United States is the issue of same-sex marriage or "marriage equality." Advocates of marriage equality eschew the term "same-sex marriage" or "gay marriage" as it denotes a separate kind of institution, something "not really" marriage.

\footnotetext{
${ }^{1}$ Omar Swartz, Ph.D., Purdue University, 1995; J.D., Duke University, 2001, magna cum laude, is Associate Professor of Humanities and Social Sciences at the University of Colorado Denver. His areas of research and teaching are law and diversity, mass media law, cultural criticism, and philosophical problems in the social sciences. Specifically, his work focuses on the intersections between the U.S. legal system and the history of social injustice and intellectual intolerance in the United States. He is the author or editor of 13 books and more than 100 essays, book chapters, and reviews. Address correspondence to: Dr. Omar Swartz, University of Colorado Denver, 1201 Larimer Street, Room 3201, Denver, Colorado 80204; e-mail: omar.swartz@ucdenver.edu.
} 